\title{
HERPES IRIS ERYTHEMA MULTIFORME MANIFESTED AFTER HUMAN HERPES VIRUS TYPE 1 (HHV-1) LABIAL INFECTION
}

\author{
Stoyan Pavlov, Zhanina Barzakova \\ Department of Infectious Diseases, Parasitology and Dermatovenereology, \\ Faculty of Medicine, Medical University of Varna
}

\begin{abstract}
Erythema multiforme (EM) is an acute, self-limiting, often recurrent disease, with or without mucosal involvement, which occurs in an IV type hypersensitivity reaction provoked by infectious, medication, physical, chemical, etc. agents. In erythema multiforme related to the human herpes virus type 1 (HHV-1) infection, the skin and mucosal manifestations are a result from a cell-mediated immune response, directed against HSV-DNA polymerase-positive antigen cells (keratinocytes).

We present a clinical case of a 33-year-old female patient with recurrent labial herpes followed by a clinical appearance of EM. About a week after the resolution the herpes recurrence, burning and itchy erythematous target lesions and blisters occurred involving upper and lower limbs, then spread to the face, neck, neckline, typical for EM. In some of the target lesions, a central blister appeared, surrounded by vesicles - herpes iris of EM type. Serology tests established high positive antibodies to HSV-1 of IgG type (154 UI/mL). Based on the characteristic clinical findings we diagnosed herpes iris erythema multiforme, related to HHV1 infection. The presented case is an interesting manifestation of the morphological type of EM, described by Thomas Bateman in 1817, "herpes iris", preceded by a relapse of the herpes infection.
\end{abstract}

Keywords: erythema multiforme (EM), human herpes virus type 1 (HHV1), Herpes iris

Address for correspondence:

Stoyan Pavlov

Faculty of Medicine

Medical University of Varna

55 Marin Drinov St

9002 Varna

e-mail: stoyanpavlov@abv.bg

Received: August 27, 2019

Accepted: September 20, 2019

\section{INTRODUCTION}

Erythema multiforme (EM) is an acute, selflimiting but recurrent disease with skin and mucosal involvement due to an IV type hypersensitivity reaction induced by infectious, medication, physical and chemical agents (1). EM was originally described in 1817 by Thomas Bateman in his dermatological atlas "Delineations of Cutaneous Diseases" as a concentric "target" or "iris"-like lesion (2). Lat- 
er in 1886, Ferdinand von Hebra distinguished EM as an acute, self-limiting but often relapsing disease, which affects symmetrically the limbs and is manifested by the characteristic target lesions (3). In 1922, American physicians Stevens and Johnson described two clinical cases in 7- and 8-year-old boys who developed generalized eruption with persistent fever, sore buccal mucosa and purulent conjunctivitis. This state was subsequently called Stevens-Johnson syndrome (SJS) $(3,4)$. In 1950, Bernard Thomas, in his article "So-Called Stevens-Johnson Syndrome", analyzed the clinical presentation of EM and proposed classification of EM into two types, according to the severity of the skin lesions: EM minor (von Hebra) and EM major, known by many researchers as SJS (5). In one of the most cited articles, published in the British Journal of Dermatology in 1956, Alan Lyell described four clinical cases ( 3 women and 1 man) with a severe bullous reaction and epidermal necrolysis, called toxic epidermal necrolysis (TEN) or Lyell syndrome, preceded by a medication treatment (6). In 1993, an international group of dermatologists proposed a new classification of the EM depending on the etiological agent (drug or infection) and the prognosis. The new classification distinguished EM minor, EM major, and SJS/TEN. EM minor and major are mostly recurrent, post-infectious (herpes simplex, mycoplasma) diseases with relatively low-grade illness and low mortality risk. SJS and TEN are druginduced reactions with severe manifestation and worse prognosis (7).

\section{CASE DESCRIPTION}

We present a 33-year-old female patient, suffering from a labial herpes with frequent recurrence of 5 to 6 times per year. One week after the current relapse of the labial herpes she was admitted in the clinic because of burning and itchy erythemic target lesions and blisters located on the upper and lower limbs and then spreading to the skin of the face, neck and neckline (Fig. 1 and Fig. 2). The lesions were found to be typical for EM. On the upper lip of the patient there was still a sign of the resolved herpes lesion - a brown oval crust of about $0.5 \mathrm{~cm}$ (Fig. 3). Vesiculobullous exanthema was accompanied by fever up to $38^{\circ} \mathrm{C}$, conjunctival redness, muscle pain and a general malaise. In some of the target lesions, central blister appeared, surrounded by the vesicles - herpes iris of erythema multiforme type (Fig. 4, Fig. 5).

Routine laboratory investigations did not demonstrate any abnormalities. Virological tests assessed

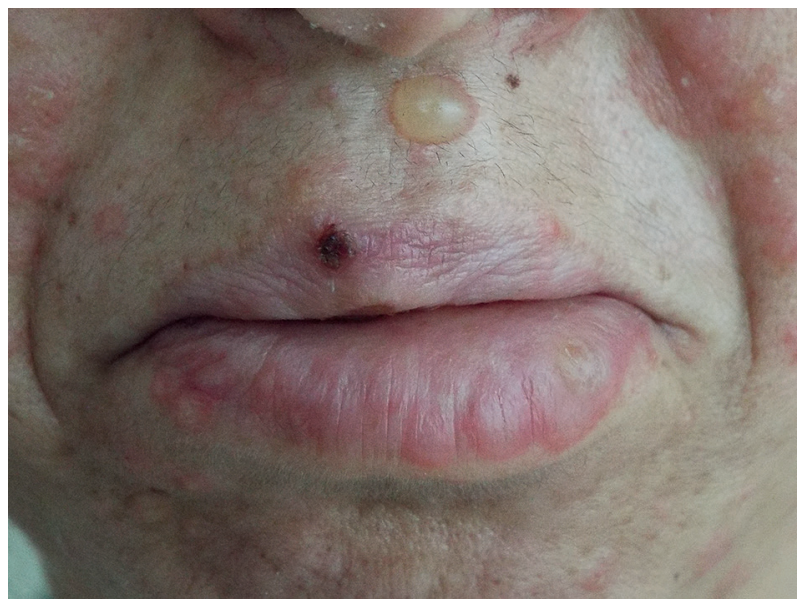

Fig. 1. Blisters

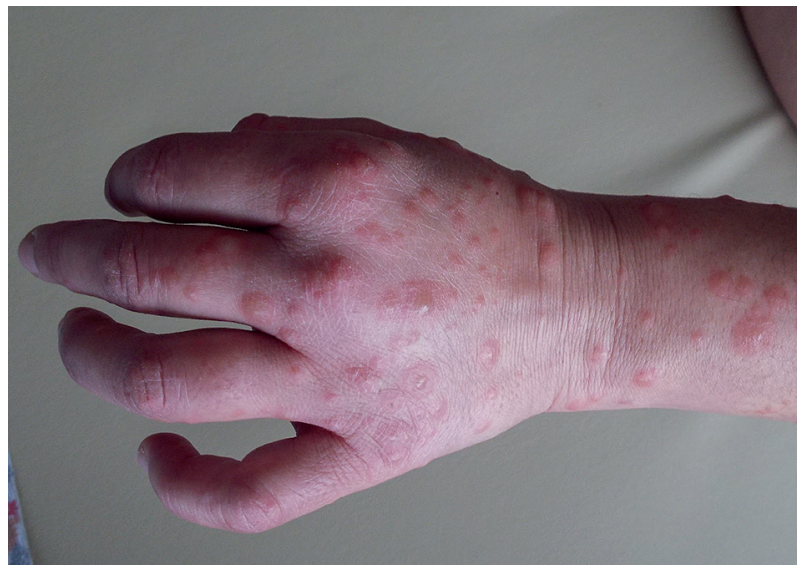

Fig. 2. Target lesions and blisters

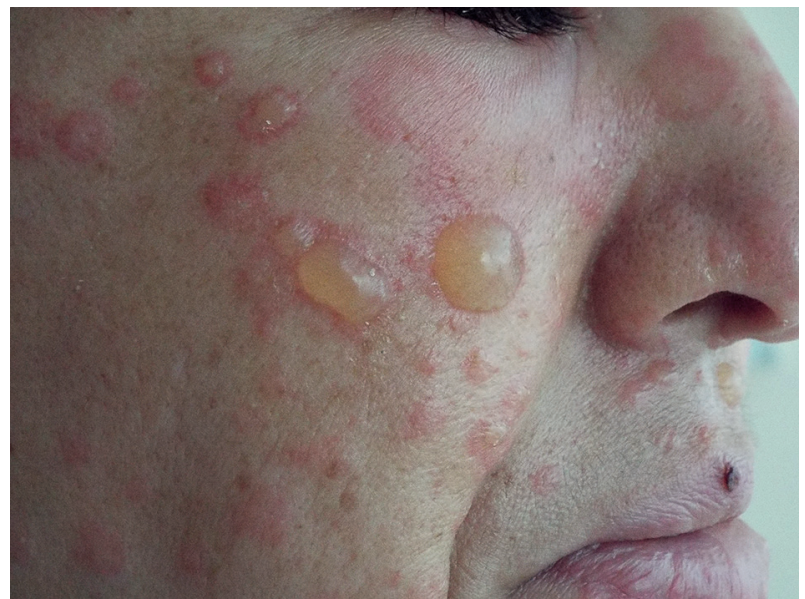

Fig. 3. Resolved herpes lesion on the upper lip 


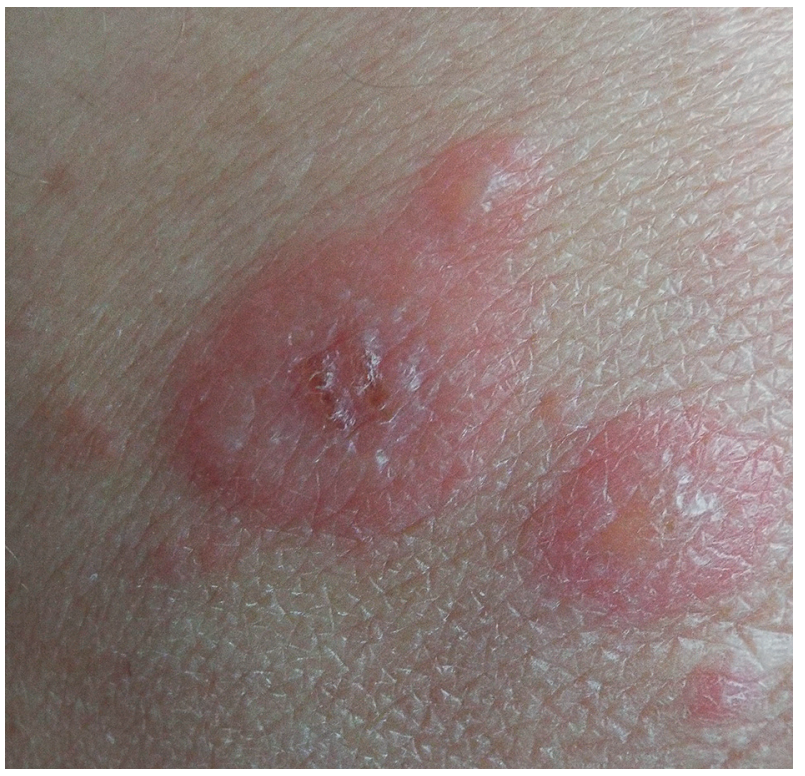

Fig. 4. Herpes iris EM type

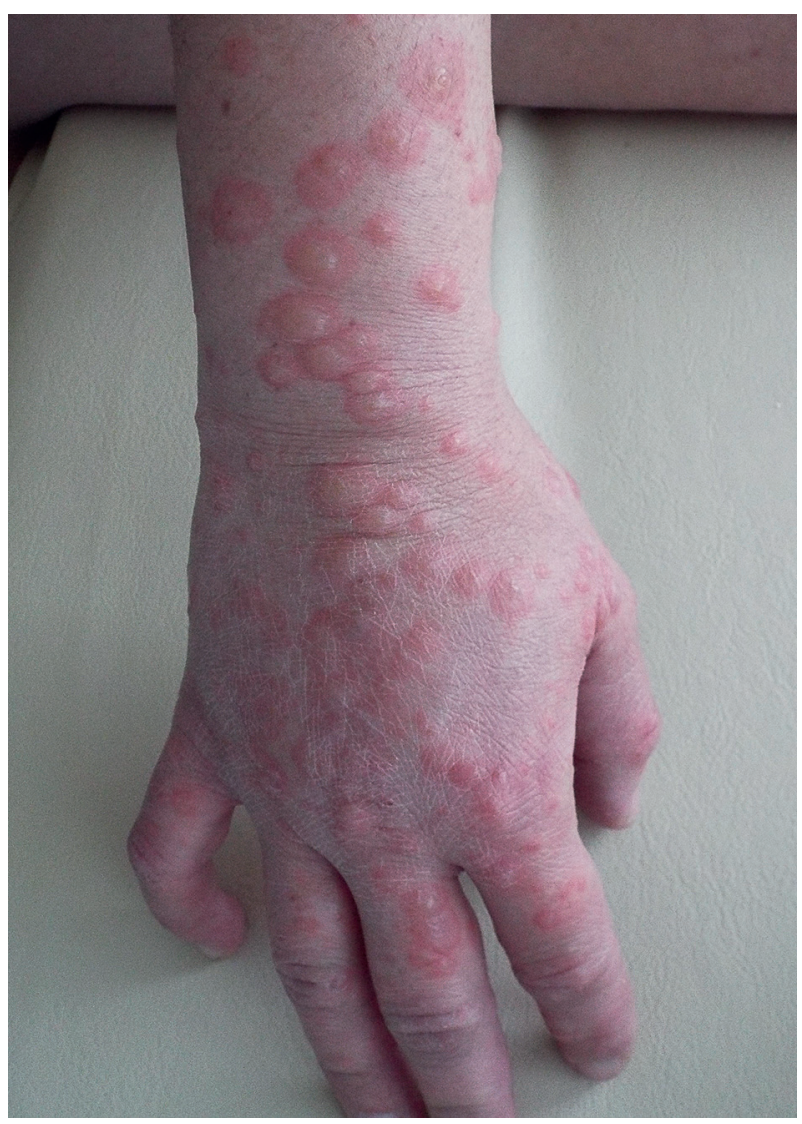

Fig. 5. Central blister surrounded by the vesicles

highly positive antibodies to herpes simplex virus type 1 (HSV-1) of IgG type (titer $154 \mathrm{IU} / \mathrm{mL}$ ), negative HSV-1 IgM antibodies, negative herpes simplex virus type 2 (HSV-2) IgM and IgG antibodies, as well as negative varicella zoster virus (VZV) IgM antibodies, HIV P24 antigen and HIV 1/2 serology. Based on the recent human herpes virus type 1 (HHV-1) labial infection, classical target lesions and conjunctival and oral mucosal involvement the diagnosis of herpes iris erythema multiforme was established.

The patient was treated with acyclovir $400 \mathrm{mg}$ orally five times per day, gentamicin $160 \mathrm{mg}$ intravenously for five days, methylprednisolone $40 \mathrm{mg}$ intravenously for three days, and methylprednisolone 20 $\mathrm{mg}$ intravenously for four days. After the treatment, skin and oral lesions were controlled. The swelling and the redness of the face healed in three days. The patient's rash and erosions were improving. On the day of discharge acyclovir was prescribed prophylactically for 30 days, $400 \mathrm{mg}$ two times per day. It is considered that in patients with recurrent EM, antiviral therapy has shown to be an effective prevention of both recurrent herpes and EM. The best response to therapy occurs in patients with a clear correlation between herpes simplex infection and EM. The dosage of $800 \mathrm{mg} / 24 \mathrm{~h}$ oral acyclovir has been shown to be effective in preventing recurrent herpes simplex. Antiviral therapy has shown to be an effective prophylaxis and can last from several weeks to several months. One month later, the patient returned with new lesions characterized by diffuse papules, single vesicle lessions and target lessions, involving her back of arms and forearms. Of note was that no history of febrile episode, conjunctival injection, general malaise or oral lessions were present this time. The patient was treated with a 7-day course of acyclovir (400 $\mathrm{mg} / 5$ times per day), methylprednisolone $4 \mathrm{mg}$ tabl. three time per day for five days. Within 7 days, all the lesions healed. Because of the recurring episodes, acyclovir was given prophylactically for one more month, $400 \mathrm{mg} / 2$ times per day. In addition, no oral or skin lesions developed 6 months after treatment.

\section{DISCUSSION}

In that case, EM is related to the recurrent HHV1 infection. This association has been confirmed in a scientific literature and HHV-DNA has been discovered in skin biopsies by the polymerase chain reaction (PCR) technique in $60 \%$ of the 63 studied patients with EM and recurrent herpes (8). The manifestation of labial herpes in our patient preceded the EM appearance by a week. A similar sequence is reg- 
istered in other studies, supporting the hypothesis of a relationship between HHV-1 and EM. The skin and mucosal manifestations of HHV1 EM are associated with cell-mediated immune reaction to HSV DNA and HSV antigens in the keratinocytes (1). The cytotoxic CD8-positive T-cell lymphocytes found in the epidermis induce apoptosis and necrosis in the surrounding keratinocytes (9). The suggested mechanism led to morphological expression, described by Thomas Bateman as herpes iris skin lesions, which are also demonstrated in the presented case. Acyclovir is an antiviral drug that penetrates HSV-infected cells. To become effective, acyclovir must first be converted to acyclovir monophosphate by an enzyme that is only found in viruses, called thymidine kinase. It is then converted to its active triphosphate form by human enzymes found inside the cells. Acyclovir triphosphate binds to and inhibits the elongation of viral DNA (10). Long-term suppressive therapy with acyclovir has been shown to decrease recurrence of HSV. Suppression of HSV can prevent HSV-associated EM (11). In the case we report, EM relapsed one month after discontinuation of acyclovir therapy. In our patient the last relapse of EM was not preceded by clinically manifested labial herpes. Probably in part of recurrences of herpes simplex, there was no full-blown clinical picture of grouped vesicular rash (12). For this reason, we assume that upon discontinuation of prophylaxis with acyclovir, subclinical activation of the virus has occurred, with subsequent mild recurrence of EM, without lesion of the conjunctiva, and without damaging the patient's general condition. Recurrence is seen in approximately $20-25 \%$ of EM cases. The recurrence rate may vary between 2 and 24 per year, lasting 10-20 days each. Typically, herpes-associated EM appears on average over 10 years and lasts between 2 and 36 years in different patients (13). Herpes-associated EM can be controlled by continuous (up to 26 weeks) suppressive treatment with oral acyclovir (200-800 mg). When acyclovir inefficiency is detected, valacyclo$\operatorname{vir}(500 \mathrm{mg}$ ) can be used 2 times per day. Valacyclovir might provide better therapeutic results and lower the risk of selecting acyclovir-resistant viral strains in patients with recurrent EM (13).

\section{CONCLUSION}

In conclusion, our clinical case illustrates and confirms the relationship between the HHV infection and EM, demonstrated with characteristic "target-like" and "herpes iris" skin changes.

\section{REFERENCES}

1. Sokumbi O, Wetter DA. Clinical features, diagnosis, and treatment of erythema multiforme: a review for the practicing dermatologist. Int J Dermatol. 2012;51(8):889-902. doi: 10.1111/j.1365-4632.2011.05348.x.

2. Levell NJ. Thomas Bateman MD FLS 17781821. Br J Dermatol. 2000;143(1):9-15. doi: 10.1046/j.1365-2133.2000.03582.x.

3. 3 Wolf R, Lipozencic J. Shape and configuration of skin lesions: targetoid lesions. Clin Dermatol. 2011;29(5):504-8. doi: 10.1016/j. clindermatol.2010.09.020.

4. Stevens AM, Johnson FC. A new eruptive fever associated with stomatitis and ophthalmia. Am J Dis Child. 1922;24(6):526. doi:10.1001/ archpedi.1922.04120120077005.

5. Thomas BA. So-called Stevens-Johnson Syndrome. Br Med J. 1950;1(4667):1393. doi: 10.1136/ bmj.1.4667.1393.

6. Lyell A. Toxic epidermal necrolysis: an eruption resembling scalding of the skin. Br J Dermatol. 1956;68(11):355-61. doi: 10.1111/j.1365-2133.1956. tb12766.x.

7. Bastuji-Garin S, Rzany B, Stern RS, Shear NH, Naldi L, Roujeau JC. Clinical classification of cases of toxic epidermal necrolysis, Stevens-Johnson syndrome, and erythema multiforme. Arch Dermatol. 1993;129(1):92-6.

8. Ng PPL, Sun YJ, Tan HH, Tan SH. Detection of herpes simplex virus genomic DNA in various subsets of erythema multiforme by polymerase chain reaction. Dermatology. 2003;207(4):349-53. doi: $10.1159 / 000074112$.

9. Huff JC. Erythema multiforme and latent herpes simplex infection. Semin Dermatol. 1992;11(3):207-10.

10. King DH. History, pharmacokinetics, and pharmacology of acyclovir. J Am Acad Dermatol. 1988;18(1 Pt 2):176-9. doi: 10.1016/s0190-9622(88)70022-5.

11. Shelley WB. Herpes simplex virus as a cause of erythema multiforme. JAMA J Am 
Med Assoc. 1967;201(3):153-6. doi:10.1001/ jama.1967.03130030023005.

12. Daikoku T, Tannai H, Honda M, Onoe T, Matsuo $\mathrm{K}$, Onoye $\mathrm{Y}$, et al. Subclinical generation of acyclovir-resistant herpes simplex virus with mutation of homopolymeric guanosine strings during acyclovir therapy. J Dermatol Sci. 2016;82(3):160-5. doi: 10.1016/j.jdermsci.2016.02.006.
13. Osterne RLV, Matos Brito RG de, Pacheco IA, Alves APNN, Sousa FB. Management of erythema multiforme associated with recurrent herpes infection: a case report. J Can Dent Assoc. 2009;75(8):597-601. 